\title{
Answer to the Letter to the Editor of J. M. Duart-Clemente et al. concerning "Systematic review of the effect of dynamic fixation systems compared with rigid fixation in the anterior cervical spine" by Campos RR, Botelho RV; Eur Spine J (2014); 23(2):298-304
}

\author{
Ricardo Rezende Campos $^{1} \cdot$ Ricardo Vieira Botelho ${ }^{1}$
}

Received: 18 October 2015/Revised: 18 October 2015/Accepted: 18 October 2015/Published online: 28 October 2015

(c) Springer-Verlag Berlin Heidelberg 2015

First of all, I would like to thank for the interest in our paper and the opportunity of continuing the discussion, clarifying further about this interesting topic.

About the questions:

First question: Ghahreman and colleagues had as main objective to evaluate the $\mathrm{ABC}^{\circledR}$ plate. This paper was not a comparative study. You suggested that "the worse fear using dynamic plate would be lordosis loss". In fact, Pitzen et al. associated greater loss of cervical lordosis in dynamic plates compared follow-up periods $(p<0.05)$. Okawa correlated dynamic plates with loss of lordosis correction and its complications. We cannot assure that the suggested amount of $50 \%$ lordosis loss would or would not be associated to greater or lower complications rate but, in several patients, correction of kyphosis is the main goal.

Regarding the second question, "the second fear is about adjacent segment irritation and subsequent early degeneration". Really, this is a potential complication of plates and your suggestions to solve this problem make sense. The studied papers did not permit conclusions about adjacent level disease and their differences in dynamic and rigid plates.

Addressing your criticism in our review, we would like to emphasize that "a systematic review is a protocol-driven comprehensive review and synthesis of published data, focusing on a specific topic".

To address your question related to the difference in several types of dynamic plates, other studies should be conducted.

Finally, the authors made their best to bring to comparison all described complications. Specific research topics must be developed to more specific questions and will contribute to the scope of knowledge.

At this point we would like to reinforce a look at the "specific points" that this paper stated in the conclusion.

\section{Compliance with ethical standards}

Conflict of interest The authors declare that they have no conflict of interest.

Ricardo Rezende Campos

ricardocampospa@uol.com.br

1 Division of Spine Surgery, Hospital do Servidor Público do Estado de São Paulo-SP, Ibirapuera Av, 931, São Paulo, SP, Brazil 